A CULTURAL-HISTORICAL PERSPECTIVE ON MATHEMATICS TEACHING AND LEARNING 
SEMIOTIC PERSPECTIVES ON THE TEACHING AND LEARNING OF MATHEMATICS SERIES

Volume 2

Series Editors

Adalira Saénz-Ludlow

Luis Radford

\author{
Editorial Board \\ Ferdinando Arzarello \\ Paul Ernest \\ Juan Godino \\ Michael Hoffmann \\ Falk Seeger \\ Carlos E. Vasco
}




\title{
A Cultural-Historical Perspective on Mathematics Teaching and Learning
}

\author{
By \\ Wolff-Michael Roth \\ University of Victoria, Canada \\ and \\ Luis Radford \\ Université Laurentienne, Ontario, Canada
}

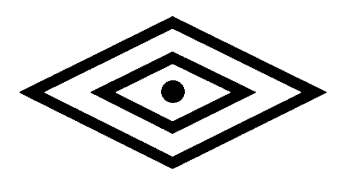

SENSE PUBLISHERS

ROTTERDAM / BOSTON / TAIPEI 
A C.I.P. record for this book is available from the Library of Congress.

ISBN 978-94-6091-562-8 (paperback)

ISBN 978-94-6091-563-5 (hardback)

ISBN 978-94-6091-564-2 (e-book)

Published by: Sense Publishers,

P.O. Box 21858, 3001 AW Rotterdam, The Netherlands

www.sensepublishers.com

Printed on acid-free paper

All rights reserved @ 2011 Sense Publishers

No part of this work may be reproduced, stored in a retrieval system, or transmitted in any form or by any means, electronic, mechanical, photocopying, microfilming, recording or otherwise, without written permission from the Publisher, with the exception of any material supplied specifically for the purpose of being entered and executed on a computer system, for exclusive use by the purchaser of the work. 


\section{Contents}

Preface vii

1 Toward a Science of the Subject 1

2 Reproduction and Transformation of Affect in Activity 29

3 Learning as Objectification 47

4 Developmental Possibilities in/from Activity 69

5 Re/Theorizing the Zone of Proximal Development 91

6 The Dual Nature of the Object/Motive 111

7 From Subjectification to Personality 127

8 A Cultural-Historical Science of Learning 141

$\begin{array}{ll}\text { Appendix } & 157\end{array}$

References 175

Index 181 


\section{Preface}

Eighty years ago, L. S. Vygotsky complained that psychology was misled in studying thought independent of emotion. This situation has not significantly changed, as most learning scientists continue to study cognition independent of emotion. Situated in activity theory - as developed by A. N. Leont'ev and Klaus Holzkamp - we investigate in this book the mutually constitutive nature of cognition and emotion. Activity theory not only stipulates the relation between individual and culture in very different ways than any other theory, but also emphasizes the constitutive role of emotions in knowing and being.

To investigate the mutually constitutive nature of cognition and emotion we draw on data from our longitudinal research program about the teaching and learning of algebra in elementary schools. We show (a) how emotions are reproduced and transformed in and through activity and (b) that in assessments of students about their progress in the activity, cognitive and emotional dimensions cannot be separated. Second, our analysis exhibits three main features: (a) the irreducible connection between emotion and cognition mediates teacher-student interactions; (b) the zone of proximal development is itself a historical and cultural emergent product of joint teacher-students activity; and (c) as an outcome of joint activity, the object/motive of activity emerges as the real outcome of the learning activity. We use the results of this study to propose (a) a different conceptualization of the zone of proximal development, (b) activity theory as an alternative to learning as individual/social construction, and (c) a way of understanding the material/ideal nature of objects in activity. This leads us to outline a subject's participation in activity and its connection to all the other activities in which a subject engages in the course of its everyday life. We conclude with a proposal for a culturalhistorical science of mathematical learning.

In contemporary research, intellect - thought, cognition - and affect tend to be different domains of study; the latter, at best, is thought of as a factor. An example of such thinking is the 'hot cognition' approach, which postulates that 'classroom contextual factors', 'motivational factors', and 'cognitive factors' influence learning and conceptual change from the outside. The problem with this line of theoriz- 
ing is that factors remain external to the sensing subject, and 'being externalities ... are indifferent towards each other, and lack the necessity for one another that ought to lie in the relation between an outer and an inner' (Hegel 1979: 236). This situation has been discussed as problematic: The separation of intellect and affect 'as subjects of study is a major weakness of traditional psychology, since it makes the thought process appear as an autonomous flow of "thoughts thinking themselves", segregated from the fullness of life, from the personal needs and interests, the inclinations and impulses of the thinker' (Vygotsky 1986: 10). This segregation is a problem because it does not allow us to understand the immediate - i.e., unmediated - influences that thought and affect have on each other. Segregating intellect and affect closes the door on understanding why the learners do what they do because there is no directionality or propensity inherent in thought that would give it a 'desire' to transform itself.

The lineage of research following Vygotsky has given rise to a different conception of the intellect-affect relation where the fullness of life, reality, is reflected psychologically as a primary sensuousness, comprising both cognition and emotion as irreducible, mutually constitutive moments. Understanding cognitive processes in learning without separating them from the affective - i.e., making the affective and the cognitive two manifestations of the same process - was a project pursued and developed in the Leont'ev-Holzkamp lineage of cultural-historical activity theory. ${ }^{1}$ In contrast to the standard interpretation of activity theory, this line of work focuses on (a) the subject of activity in relation to society and (b) consciousness as a superordinate category to which cognition and emotion are subordinated. Vygotsky had asked for 'unit analysis' of a 'dynamic system of meaning in which the affective and the intellectual unite' (Vygotsky 1986: 10). An analysis of the unit reveals that there is a 'transmuted affective attitude toward the bit of reality' to which an idea refers.

In this book, we develop a conception of teaching and learning mathematics that is very different from two available standard conceptions. On the one hand, there is the Piagetian individual who rediscovers through his/her own actions the rationality of mathematics; on the other hand, there is the (deficient) individual as empty vessel, who comes to be filled with the knowledge that culture makes available. Newer conceptions combine the two but nevertheless substantialize the individual and the collective (culture) and place them in an interactional relation. The purpose of this book is to articulate the role of emotion in teaching-learning activity, where it, as an index for the subjective valuation of the current state of the activity, is both reproduced and transformed. Affect, as Vygotsky points out, is essential in an understanding of knowing as a process that transforms itself. Similarly, we show that the very object/motive that drives the learning activity is accessible to students

\footnotetext{
${ }^{1}$ Much of this work is not available in English. But there exists a good introduction to Holzkamp's theory (Tolman 1994) and an edited volume presents major contributors to this theory (Tolman and Maiers 1991). The best-known member of this lineage publishing in English probably is Ole Dreier (e.g., 2008). Mutual references in a number of works between K. Holzkamp (e.g., 1993) and J. Lave (e.g., 1993) also suggests an affinity between the works of the two scholars.
} 
only as an outcome of the activity, which, when it involves the teacher, also allows the zone of proximal development to emerge.

This book is the result of several research programs funded by the Social Sciences and Humanities Research Council of Canada (SSHRC/CRSH).

Victoria, BC \& Sudbury, Ont. January 2011 